\title{
Desconstruindo o heterocentrismo da violência nas relações conjugais
}

\author{
Mailiz Garibotti Lusa
}

Universidade Federal de Santa Catarina (UFSC)

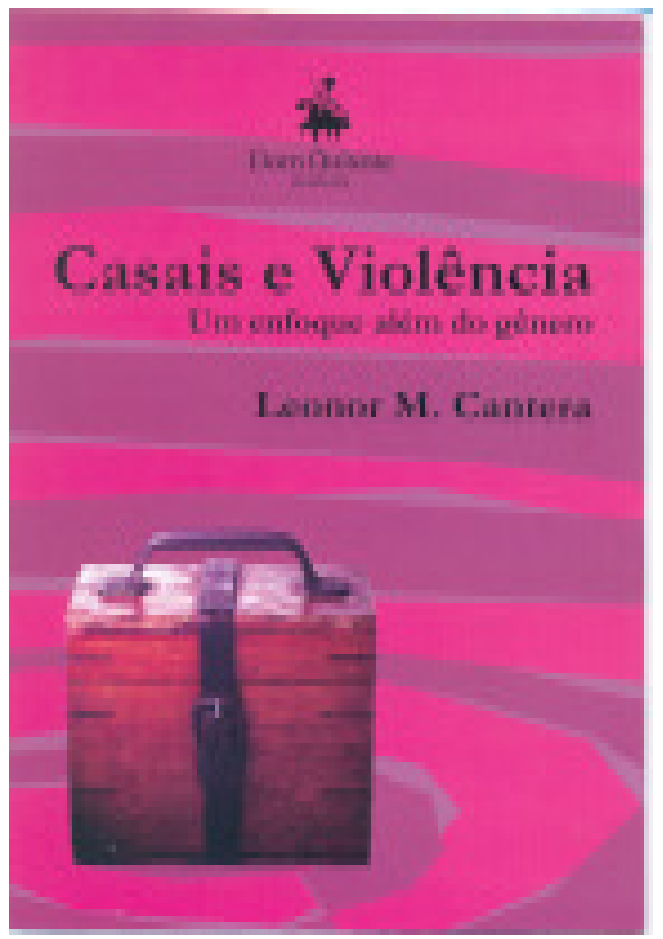

RESENHA: Desconstruindo o heterocentrismo da violência nas relações conjugais

CANTERA, Leonor M. Casais e violência: um enfoque além do gênero. Porto Alegre: Dom Quixote, 2007. 208p.

BOOK REVIEW: Deconstructing the Hetero-centrism of Violence in Conjugal Relations CANTERA, Leonor M. Couples and Violence: Looking Beyond Gender. Porto Alegre: Dom Quixote, 2007. 208p. 
O debate sobre a violência familiar e a violência contra a mulher no âmbito doméstico tem ocupado lugar de relevância nos espaços públicos, nos estudos acadêmicos e na pauta de luta dos movimentos sociais nos últimos anos. Nestes, fica marcado expressamente $\mathrm{o}$ ano de 2006, quando foi sancionada a Lei 11.340 (Lei Maria da Penha) pelo Presidente Luís Inácio Lula da Silva.

Uma das nuances desses debates é "a violência nas relações conjugais", tema aprofundado no decorrer da obra de Leonor Maria Cantera Espinosa, pesquisadora do Departamento de Psicologia Social, da Universidade Autônoma de Barcelona.

No decorrer de seus estudos, a autora constata que a violência entre casais acontece tanto em relações heterossexuais como homossexuais. Além disto, desmistifica que em casais heterossexuais a violência parte sempre do homem em direção à mulher, mostrando que há situações em que é a mulher quem violenta o seu companheiro.

Outro traço sublinhado pela autora refere-se à invisibilidade das violências cometidas entre casais homossexuais, tanto gays como lésbicas, já que estas experiências são ocultadas em razão de que não seja revelada a orientação homossexual. Esta constatação é premente para legitimar o fato de que, atualmente, vive-se num contexto de heteronormatividade, heterossexismo e de homofobia. Destarte, torna-se preocupante que na sociedade possa ocorrer uma auto-ocultação da violência sofrida nestes casos, a fim de evitar a dupla estigmatização social, num meio em que a discriminação reside tanto na própria violência sofrida, quanto na orientação sexual do sujeito agredido.

A obra de Cantera resulta de uma pesquisa de base bibliográfica, apresentando um panorama conceitual associado a um estudo empírico que teve como sujeitos diferentes tipos de casais que vivenciaram situações de violência em suas relações conjugais heterossexuais ou homossexuais. A pesquisa, de caráter exploratório, foi desenvolvida ao longo de 2003-2004 em Barcelona, Espanha. Foi estudado um universo de 136 pessoas, sendo 56 homens e 80 mulheres: 83 heterossexuais e 53 não heterossexuais - dado este que, segundo a autora refere-se "a gays, lésbicas e em alguns casos isolados, categorias que não se encaixavam em uma dicotomia convencional 'homo'/'hetero'."

A entrevista semi-estruturada, em que foram focalizadas as experiências de violência, foi aplicada com 12 pessoas vítimas de violência nas relações conjugais, selecionadas segundo os critérios de tipo de casal; forma de violência e direção da mesma. Foram feitas perguntas fechadas que versaram sobre nível socioeconômico, capital emocional, clima psicossocial, realização sexual e afetiva, situação sociolegal, diferenças econômico-trabalhistas; assimetrias interpessoais, recípocras negativas (tais como infidelidade emocional, desconfiança mútua ...), facilitadores diversos da violência e tensões gerais na vida conjugal. Nas perguntas abertas da pesquisa a abordagem foi sobre o "casal ideal", histórias de maus-tratos, motivos, justificativas, semelhanças e diferenças quanto à violência entre casais heterossexuais e homossexuais e a protagonizada por mulheres e, para concluir, o que dificulta ou facilita a saída de uma relação de maus-tratos.

De forma geral a pesquisa apontou que é dado elevado valor ao "casal", o que demonstra que viver um relacionamento conjugal concede uma identidade social ainda desejada. Dentre os tipos de relacionamentos foram mais valoradas as relações heterossexuais, que as não-heterossexuais, explicitando uma avaliação heterocentrista, seguindo inclusive, os estereótipos de gênero. Percebeu-se que homens e mulheres pensam com similaridade os "fatores de harmonia e violência" no casal e que ambos, apesar de dizerem que nada justifica a violência, atribuemna ao álcool, às drogas, a problemas econômicos ou trabalhistas, à infidelidade, a ciúmes, caráter. Também se observou que "a violência entre casais heterossexuais é mais freqüente, física e intensa" e que os fatores que mais interferem na continuidade de uma relação conjugal violenta são: dependência econômica, pressão social, sentimento de culpa, medo da solidão ou represálias, entre outras.

Nesta interlocução entre dados conceituais e empíricos, resgata-se alguns paradigmas críticos, que seriam segundo a própria autora "herdados", os quais auxiliam na compreensão de como a violência entre casais acontece, é estudada, discutida e definida desde que os movimentos feministas, a comunidade científica, a opinião pública e os mais diversos organismos internacionais começaram a desprender esforços a fim de conceder relevância ao tema. Dentre eles, destacam-se o "patriarcado", o "casamento", "os estereótipos de gênero", "a violência de gênero" e principalmente o próprio "olhar /perspectiva de gênero".

É neste ínterim que a autora apresenta uma autocrítica ao olhar de gênero e às demais concepções, ressaltando quão importantes foram e ainda são para as discussões de até então. Por outro lado, torna-se imprescindível desafiar novos olhares que possam contribuir para o desenvolvimento de outros paradigmas pertinentes, que possibilitem maiores avanços nos debates e na formulação de políticas na atualidade.

Em relação ao "patriarcado", a pesquisa reconhece que dentro do grupo de acadêmicos que se dedicam aos estudos feministas, reside uma polêmica a respeito de sua utilização como perspectiva de análise deste campo. Constata que esta categoria passa a ser utilizada seja para compreender a lógica pela qual aconteceu e persiste a dominação masculina na maioria 
das sociedades, seja para contrapô-lo a uma forma de relações sociais com maior eqüidade, a qual por hora continua como um horizonte a ser conquistado.

Ao resgatar os avanços do último século, no que tange aos direitos e espaços das mulheres nas sociedades e a própria visibilidade da violência cometida contra a mulher, o trabalho destaca que houve um processo de "desnaturalização, desprivatização, desindividualização, desbiologização e desnormalização" das situações que colocavam a mulher num patamar desprivilegiado em relação ao homem. Entretanto, um resultado foi a redução da problemática da violência no casal como "mera questão de gênero a ser resolvida."

A partir do reconhecimento da conexão direta entre tais avanços e suas conseqüências - denominadas pela autora como uma espécie de "efeito colateral desse transcendental processo de sensibilização e conscientização social"-, é possível analisar quais são as faces que a violência pode assumir entre casais, desmistificando o fato de que exista somente um tipo de casal, uma forma de violência e uma única direção de ocorrência que é "do homem -agressor para com a mulher-vítima."

São perpassadas as várias formas de violência vivenciadas entre casais e as funções que estas tais violências exercem no contexto capitalista de produção de riquezas e de reprodução de mão-de-obra, as quais vão desde a violência física, até a violência psicológica no campo de trabalho.

É dentre estes diversos tipos de violência, que se encontra àquela praticada através da própria divisão sexual do trabalho e, consequientemente (neste caso), da submissão da mulher pelo homem no âmbito do trabalho. Além deste, outros tipos de violência são denunciadas, como por exemplo, àquela praticada pelo Estado através de suas instituições, as quais ontologicamente teriam como função o atendimento de cidadãos homens e mulheres, mas que, no entanto, acabam por incorporar a própria lógica da violência, que dificilmente tornase pública (visível) na sociedade.

Para a autora, uma considerável contribuição para os debates da área está no fato de que a violência entre casais é retirada da esfera de "assunto privado" e é colocada como "questão social", fruto de vivências de masculinidades e feminilidades construídas sócio-culturalmente. Indica-se que antes de tudo é necessário que tal violência seja compreendida, para somente depois desmistificá-la enquanto uma normatização das relações conjugais.

Ao tratar especificamente da violência contra a mulher, fica sobressalente as interações que o fator "gênero" possui com outros fatores, tais como "etnia", "classe social", "nacionalidade", "orientação sexual", "idade", indicando assim possíveis motivos porque determinados coletivos de mulheres são mais ou menos vulneráveis à violência. Nota-se aí que a pesquisadora, ao fazer uma autocrítica à perspectiva de gênero, não deixa de utilizá-la para compreender e indicar tratamentos para a violência conjugal sofrida especificamente por mulheres em relações heterossexuais ou não-heterossexuais.

Assim, é necessária a desconstrução da própria visão sobre a violência entre casais para que seja possível compreender que a mesma é uma "forma de conduta socialmente apreendida, mas que pode ser modificada", que ela é praticada por todo tipo de pessoas, inclusive por instituições (Estado) e que é assunto público, social, político e moral.

Enfim, ao visitar conceitos normatizados, constatar a existência de formas invisibilizadas de violência no casal, dar voz aos sujeitos destas violências e apontar questionamentos, abrem-se perspectivas para o tratamento desta face da questão social.

Logo, no momento em que a própria Lei Maria da Penha ainda se configura como um assunto que demanda maiores discussões acerca da sua aplicação, indica-se a relevância da obra para todas aquelas e aqueles pesquisadores, e/ou trabalhadores sociais, que em seus cotidianos profissionais deparam-se com tais situações geradas nas relações sociais de conjugalidade heterossexual e não heterossexual.

\section{Mailiz Garibotti Lusa}

Acadêmica de Serviço Social (UFSC)

Bolsista de Iniciação Científica PIBIC-CNPq

Orientadora: Teresa Kleba Lisboa

\section{UFSC}

Departamento de Serviço Social

Núcleo de Estudos e Pesquisas em Serviço Social e Relações de Gênero (Nusserge)

Campus Universitário Reitor João David Ferreira Lima

Trindade - Florianópolis - Santa Catarina CEP: 88010-970 